Psychology of Language and Communication 2019, Vol. 23, No. 1

\title{
Sciendo
}

DOI: $10.2478 /$ plc-2019-0015

\author{
EWA MARTA DRYLL \\ University of Warsaw, Warsaw, Poland
}

\section{METAPHORICAL DESCRIPTIONS OF WELL-DOERS}

\begin{abstract}
What is a metaphoric picture of a "well-doer" made of? In a study devoted to the development of the ability to use metaphorical descriptions of humans, I tried to establish the semantic fields of four target metaphors: Human-Apple Tree, Human-Sun, Human-Cup, Human-Dolphin. Over 300 young adults (the exact number depending on the stimuli), both men and women aged 19-26, were asked to decipher the metaphors' meanings. The results were obtained mainly by qualitative analysis, with frequency counts of clusters containing synonymous meanings. The results indicate that, while creating imaginary characteristics of "“kind humans," young adults focus on three factors: benefactor provides help (which takes various, but consistent forms: he/she gives hope, an ear to listen to one's problems, shares fruits of work, provides warmth and joy, etc.), benefactor's mental stability (as opposed to sudden changes of mood, which is associated with weakness), benefactor's skill of merging cheerfulness and tranquility. The semantic fields of stimuli addressed to kindness are more complex than the ones connected with evil. Goodness may be associated with wisdom, maturity, generosity, with both inactivity and vividness. Beauty seems to be less important than was expected. The results may serve for developmental comparisons.
\end{abstract}

Keywords: metaphor, kindness, characterizing humans, nonliteral descriptions, semantic fields

Questions such as "Who is good?", "Which deeds are benevolent?", "What makes humans act kindly towards each other?", etc., certainly have a history. The presented paper does not offer any proper summary on the subject; it would be impossible due to the complicity and capacity of the topic. We can, however, focus on the question, "What is the metaphoric picture of a welldoer composed of?" As Pizarro and Tannenbaum (2011) put it, "Few tasks are

Address for correspondence: Ewa Marta Dryll, University of Warsaw, Stawki 5/7, 00-183 Warsaw, Poland. E-mail: edryll@psych.uw.edu.pl 
as important to our social well-being as figuring out who the 'good guys' and the 'bad guys' are in our everyday lives" (p. 91). And nonliteral descriptions have very specific impact on communicating complex characteristics.

\section{Theoretical Background on Researching Who the Well-Doers Are}

The results of studies conducted in the 1960s and 1970s show that the way in which an individual perceives 'kindness' changes with age. That conclusion is not surprising. Here, the first thought would probably be the stages of moral development according to Lawrence Kohlberg, his widely known Heinz dilemma, and the multiple variations that followed (Colby et al., 1983). In an article published in 1982, Herbert Saltzstein and Alan Weiner say that the most researched phenomena in moral cognition is probably children's increasing use of intentions and motives as well as decreasing use of outcomes to morally evaluate action. The authors point out that relatively little is known about the acquisition of the ability to make moral evaluations and the processes involved. Nearly 20 years after their publication, in 2001, Daniel Lapsley and Benjamin Lasky comment:

For many decades, the moral dimension of selfhood, character, and identity has been largely neglected by researchers. Although the relative neglect of these constructs has a number of sources, there is little doubt that the ascendance of the cognitive developmental tradition, particularly Kohlberg's (...) account of moral development, has done much to push these topics to the margins of moral psychological research. For example, Kohlberg's embrace of a Kantian vision of moral rationality led him to emphasize the deontic (duty) aspect of morality at the expense of aretaic (excellence) concerns regarding the cultivation of virtues or traits of character. The emphasis was on "What ought I to do?" rather than "What sort of person should I become?" (Lapsley \& Lasky, 2001, p. 345).

However, that comment offers a shortcut. Although Kohlberg's domination is beyond doubt, some authors of that time believed that moral development may have different patterns. For example, in 1968, Myrna Beth Shure asked 80 children (4-, 6-, 8-, and 10-year-olds) and 40 college students to make judgments on stories about fairness, generosity, and selfishness in specific situations. In adults, the highest agreement was found with respect to concepts of fairness and the lowest with respect to concepts of selfishness. Shure says that, in general, the concepts for which there was the highest agreement in adults were developed the earliest in childhood (for more examples of dilemma-specific results on moral judgement and pro-social behavior, see also Baldwin \& Baldwin, 1970; Levin \& Bekerman-Greenberg, 1979). Other authors have warned that too much may depend on methodology: They have spotted differences in moral judgement that could be linked strictly 
to the way of presenting stimuli. For instance, the results of a study conducted by Michael Chandler, Stephen Greenspan, and Carl Barenboim (1973) show that children seem to respond differently to various formats of presenting moral dilemmas. In their study (conducted on eighty 7-year-olds), moral dilemmas were prepared in the verbal format or in a format of a movie with children as actors. Each subject was shown one verbal and one videotaped story. Authors report that the moral judgments made in response to the verbal dilemmas were largely focused on consequences, but responses to the filmed dilemmas were largely based on intentions. They suggest that previous findings indicating that young children are unresponsive to issues of intentionality are methodological artifacts.

Contrary to popular view on classical research, the development of moral judgement was not necessarily seen as 'hibernated' in teenagers. An example from that era: in "Understanding Moral Thought: Effects on Moral Reasoning and Decision Making," Richard Weiss (1982) tested 16-18-year-olds for understanding of processes involved in moral reasoning and decision making in relation to the subjects' level of moral reasoning, extent of prudential concerns, and consistency of decision making. The author established four qualitatively different levels of understanding of moral thought. Subjects were presented with dilemmas involving a fictitious other or the self as the protagonist. Participants estimated to have less understanding of moral thought were more likely to demonstrate more prudential concerns in each perspective, marked lower moral scores, and were prone to changing decision in the self-perspective. Subjects who switched their decision in the self-perspective had lower selfperspective moral scores than those who showed decision consistency. Weiss interprets his results thus: Subjects with less understanding of the processes involved in moral thought are more likely to use reasons in the service of decisions they want to make for prudential concerns.

Research conducted on adults also shows various differences in moral judgement and declared readiness for altruistic behavior. From then to now on, multiple factors were included - for example, moral endo- and exocentrism (Karylowski, 1982), moral domains (Graham et al., 2011; Young \& Saxe, 2011), causal and intentional analyses in moral judgment (Cushman, 2008), conscious and intuitive moral reasoning (Cushman, Young, \& Hauser, 2006; Gray, Young, \& Waytz, 2012), social cognition in the attribution of moral responsibility (Woolfolk, Doris, \& Darley, 2006), variance in moral conviction (Skitka, 2010). Even the ways in which morality shapes perception - here, we can find examples of conclusions like "individuals high in trait disgust sensitivity and people exposed to disgusting stimuli are selectively better at detecting a digit presented one shade lighter than the background color. Although this work does not test the effect of morality directly, it does suggest that moral emotions, such as disgust, can alter detection" (Gantman \& Van Bavel, 2015, p. 631). All of these authors use sophisticated methods of analysis. 
According to David Tannenbaum, Eric Uhlmann, and Daniel Diermeier (2011), the authors of "Moral Signals, Public Outrage, and Immaterial Harms (2011)," recent research suggests that the primary factor in moral judgement is the person perception, not the evaluation of deontic permissions or of the outcome of instigated actions. As the authors say, evaluations of people are employed automatically and effortlessly: They develop at remarkably early stages of life and the focus is most pronounced in the moral domain. They believe that their results demonstrate dissociation between moral evaluations of people and of their actions (e.g., although violence toward a human was viewed as a more blameworthy act than violence toward an animal, the latter was regarded as more revealing of bad moral character). That is why, in the authors' opinion, strong moral reactions can occur in reaction to relatively harmless acts, if they provide highly diagnostic information about a moral character. More importantly, the text includes suggestions that the basic dimension of person perception is an individual's warmth or benevolence. When asked to describe the qualities of a moral person, people view both a sense of integrity and a capacity for empathy as crucial aspects of moral character. The authors cite results of studies examining the component parts of warmth judgments. They find that traits related to the morality component (e.g., honesty, sincerity, and trustworthiness) are dominant in forming global impressions of others relative to other components of warmth. One might be curious, however, if sincerity etc. is indeed widely recognized as a subscale of warmth.

In Brambilla and Leach (2014) and Brambilla, Rusconi, Sacchi, and Cherubini (2011), warmth is regarded as a "communion dimension" and is composed of, among others, friendliness, kindness, cooperativeness, and trustworthiness. It is addressed to benevolence, as it serves to indicate whether someone's intentions are beneficial or harmful. In contrast, the "agency dimension" refers to performance and influence. It involves qualities such as efficiency, intelligence, strength, capability, etc. and indicates whether someone has the ability to carry out their intentions. The results add to the theoretical claim that warmth and competence are the two fundamental dimensions of social judgment, and that the moral component of warmth has a primary and a dominant role in information gathering about others. In Brambilla et. al (2011), designed to find out which traits were mostly selected when forming impressions about others, the results showed that traits related to morality and sociability were differently processed. When asked to form a global impression about others, the participants seemed to be more focused on information about morality than about sociability (see also Brambilla \& Leach, 2014). Similar results were obtained by Oscar Ybarra, Emily Chan, and Denise Park (2001), who also claim that adults are more sensitive 
to warmth information than to competence information. The authors used lexical decision tasks to show that warmth-related trait words were identified faster than competence-related trait words.

Daniel Lapsley and Benjamin Lasky (2001) tried to test whether moral character is organized as a cognitive prototype. First, they asked the participants to list as many attributes of a "good character" as they could think of. Then, the synonyms were combined, compound phrases divided into separate descriptors, nouns converted to adjective forms, and the modifiers dropped. This yielded a list of 175 unduplicated trait adjectives. Then, another group of participants rated each trait on its centrality to good character. The analysis led to establishing the list of 20 trait attributes with the highest prototypicality ratings as central to the good character prototype: understanding, moral, kind, caring, supportive, respectful, faithful, friendly, fair, trusting, considerate, loyal, sincere, loving, compassionate, genuine, responsible, trustworthy, reliable, and honest. And the 20 peripheral trait attributes of a good character: lucky, clean, popular, proud, shy, objective, provocative, introspective, opinionated, intelligent, thrifty, charismatic, classy, energetic, talkative, outgoing, patriotic, modest, healthy, and independent. After that, the authors checked whether the subjects reported more false recognition of trait attributes that they have not seen but that were consistent (virtue central) with the prototype. Since the participants reported significant false recognition of novel virtue-central traits better than they did virtue-peripheral traits, the authors concluded that a conception of good character is schematically organized around a prototype. Integrity and empathy have been conceptualized alternatively as key components of one broader dimension of moral character.

Lawrence Walker and Karl Henning (2004) also used the free-listing procedure. They obtained attributes of three moral virtues: just, brave, and caring. Then, they applied prototypicality- and personality-rating procedures as well as similarity-sorting procedure. The goal was to identify the typologies implicit in people's understanding. According to the authors, the findings indicate that moral excellence can be exemplified in divergent ways and that understanding of moral functioning would be enhanced by attention to this wider range of moral virtues. It is most interesting that some sets were unique to particular concepts whereas others were shared: There were 50 unique descriptors for a "just person" (e.g., listens to all sides, has integrity, reasonable), 67 for a "brave person" (e.g., heroic, intrepid, faces danger), and 47 for a "caring person" (e.g., good-hearted, supportive, nurturing). Among these, 15 descriptors were exclusively shared between a "just" and a "brave" person (e.g., honorable, courageous, principled), 18 were shared between a "just" and a "caring" person (e.g., good listener, fair, concerned), and 8 were items of both, a "brave" and a "caring" person (e.g., self-sacrificial, dedicated, altruistic). Apart from that, 30 descriptors were common to all three sets. 
Susan Fiske, Amy Cuddy, and Peter Glick, the authors of "Universal Dimensions of Social Cognition: Warmth and Competence" (2007) as well as "Warmth and Competence as Universal Dimensions of Social Perception: The Stereotype Content Model and the BIAS Map" (2008), say that warmth and competence are two universal dimensions of social cognition as they provide fundamental social structural answers about competition and status. The results of their theoretical meta-analysis indicate that people perceived as warm and competent elicit uniformly positive emotions (whereas those believed to be lacking warmth and competence are generally disliked and mistrusted). People differentiate each other by liking (warmth, trustworthiness) and by respecting (competence, efficiency). Those classified as high on one dimension and low on the other stir ambivalent, yet predictable, affective and behavioral reactions. Warmth judgments are to be primary: Warmth is judged before competence, and warmth judgments carry more weight. But again, what exactly is warmth? In the authors' view, the warmth dimension captures traits that are related to perceived intent (here: friendliness, helpfulness, sincerity, trustworthiness and morality) whereas the competence dimension contains traits associated with perceived ability (intelligence, skill, creativity, efficacy, etc.). It is worth noticing that warmth-trustworthiness overlaps with moral traits like fair, generous, helpful, honest, righteous, sincere, tolerant, and understanding. As it often goes with meta-analysis, the summary is much appreciated, but a reader yearns for a bit more precision.

It seems that in recent years, the most popular issue is connected to the fact that moral development starts much sooner than the classical authors used to believe (Bloom, 2013; Hamlin, Wynn, \& Bloom, 2007), and the main points here are based on children's willingness to share and their sensitivity for help giving (Peterson, 1980; Peterson, Hartmann, \& Gelfand, 1977; Sims, 1978; Smith, Gelfand, Hartmann, \& Partlow, 1979). Since the research on adults points towards the importance of warmth, empathy, and integrity in a picture of a good person, it seems that these factors are primal and should be expected in a metaphoric picture of a "well-doer" or a "kind person." These results also indicate that these problems should be approached with various forms of tools (verbal, filmed, drama, cartoons, and with literal and nonliteral stimuli).

\section{Why Metaphors?}

Figurative language is most often used to talk about things that are both important and subtle. Metaphors facilitate cognitive discoveries and provide speakers with tools to name them. Various authors enlisted the main great values of metaphors. Raymond Gibbs (2002) says that they are a particularly compact means of communication, they provide a way of expressing ideas that would be extremely difficult to convey using literal language and they help communicate the "vividness of our phenomenological experience" (p. 125). 
To add a point from a different perspective, in a text devoted to the functions of key metaphors in early Quaker sermons (dated 1671-1700), Michael Graves (1983) describes their role as means of (a) summarizing the world in a way that would make psychological and theological sense to the speakers and receivers; (b) elaborating on the implications of shared beliefs; (c) creative tools, readily adapted for rhetorical improvising during the delivery. In other words, metaphors in sermons were used to talk about ultimate goodness, human's search for absolute truth and all the absurdity perceived in the imperfect world.

Whereas rational and formal reasoning should be devoid of contradictions, people must often handle conflicting perspectives in everyday contexts. Using figurative language to describe one's social environment seems to be a crucial skill, gained over years of cognitive development (Białecka-Pikul, 2003; Dryll, 2009, 2017; Dryll \& Bokus, 2016; Hamlin et al., 2007; Kubicka, 2005; Littlemore \& Low, 2006). According to Samuel Glucksberg (2008), potential nonliteral meanings are always taken into account and metaphor comprehension is automatic. Sources indicate that some disorders or severe mental states (e.g., autism spectrum disorder, depression, etc.) may be connected with difficulties that people experience when trying to process metaphors (Bartczak \& Bokus, 2013; Nippold \& Fey, 1983; Pisula, 2003).

The functions are complex, but what is known (so far) about the processes behind metaphor comprehension? The mechanism is probably based on noticing a surprising similarity between items that belong to different domains: When processing a metaphor, one thinks about one item (the topic) in terms of a completely different item (the vehicle), and, at that moment, one grasps the feature that makes the topic and the vehicle similar to each other (Kubicka, 2005). However, metaphors cannot be reduced to plain similes (Glucksberg \& Haught, 2006; Kennedy \& Chiappe, 1999; Ortony, 1979; Ortony, Vondruska, Foss, \& Jones, 1985). It is probable that noticing one connection between the two objects leads to establishing not one link, but a network of associations (Glucksberg, 2003, 2008; Veale \& Hao, 2007; see also Black, 1979) or metaphorical mappings (Boroditsky, 2000). Therefore, activating several domains influences cognitive processes in a deeper and broader way, then if metaphors were just a plain rhetorical trick (Glucksberg \& Keysar, 1990; Noveck, Bianco, \& Castry, 2001; Ortony, 1993).

Perceived connection is communicated and deciphered. Here, the receiver analyzes various factors - to name only a few: aptness, familiarity, conventionality, etc. (Chiappe, Kennedy, \& Chiappe, 2003; Gentner, 1983; Gentner \& Clement, 1988; Gibbs, 2001; Markman \& Gentner, 1990). Aptness seems to be crucial in novel (vivid) metaphors (Chiappe, Kennedy, \& Smykowski, 2003). Some of that "cogni-linguistic" discoveries will become conventional (dead) metaphors if adapted by a larger group of competent language users, used often, and passed on to new speakers 
(Ricoeur, 1978; Rudnicka, 2004). But metaphors are seldom wholly original or completely conventional. Rather, they are original in a given context or among a given group (Dryll \& Bokus, 2018).

Readers acquainted with Lakoff and Johnson's (1980) theory of metaphor probably remember that "good is up." That idea is still being replicated (see, e.g., Gottwald, Elsner, \& Pollatos, 2015), but it will not be discussed here since it has very little to do with human character.

\section{Current Study and Research Question}

The research question of the present study is aimed at establishing the semantic fields of metaphors addressed to a "good human." The results are supposed to serve for future developmental comparisons.

\section{Method}

\section{Participants and Procedures}

The results presented here are only a slice of wider research on the development of the ability to use metaphorical descriptions of humans, which was designed as a doctoral study (Dryll, 2017; Dryll \& Bokus, 2016, 2018). The project was planned as a cross-examination, comparisons between age groups. It was focused on observing similarities and differences in subjects' understanding of figurative meanings, in hopes of formulating hypotheses concerning various aspects of cognitive, linguistic, and social development. It was essential to begin with establishing the meaning of a small number of metaphors - ones that are present in the contemporary cultural context. The aim of the first main study was to decipher 26 metaphors as they are understood by competent language users (i.e., educated adults). The meanings indicated by adults were to be the true meaning of a metaphor. The list of stimuli was composed to include both conventional and original metaphors. All the answers were analyzed and counted. Uncovering 26 semantic fields of the 26 metaphor stimuli required collecting the fullest possible scope of associations.

The second main study was devoted to children, adolescents, and their understanding of those 26 metaphors. Subjects belonged to four age groups: younger $\left(M_{\text {age }}=6.7\right.$ years $)$ and older $\left(M_{\text {age }}=8.9\right.$ years $)$ children from elementary school, younger adolescents (first year of middle school), and older adolescents (first year of high school). The aim of this study was to gather results that would allow comparisons between the meanings described by adults and the meanings described by younger language users. These results will not be discussed here (for details, see Dryll \& Bokus, 2016). 


\section{Participants and Procedures}

The subjects were young adult students recruited from the University of Warsaw, in particular, from the Faculty of Psychology (388 participants; 39 men, 349 women; $M_{\text {age }}=20.8$ years) and the Faculty of Journalism (78 participants; 23 men, 55 women; $M_{\text {age }}=22.4$ years), and also from the Warsaw School of Economics (31 participants; 20 men, 11 women; $M_{\text {age }}=21$ years). The results of the pilot studies did not indicate significant differences in male and female participants' answers. As mentioned above, every answer was precious, therefore the results of the pilot studies have been included in the final picture of 26 semantic fields. That is why the number of subjects answering some of the stimuli differs (for details and results, see Dryll, 2017; Dryll \& Bokus, 2016). All participants followed the same procedure. They responded to 26 metaphorical stimuli listed in a tool described below.

\section{Research Tool}

The tool for the study had to be designed. In short, in the very first pilot study, the subjects were asked to think of metaphors that are (or could be) used to describe people as "evil" or "good," "smart" or "stupid," etc. It led to working on the vehicles chosen by the subjects (again, for details, see Dryll, 2009; Dryll \& Bokus, 2016). The results indicated that adults use various categories of description, and that these categories are related to the dimensions of human characteristics. After various transformations, this procedure enabled the selection of 26 stimuli from four domains: animals, plants, everyday objects, and elements of landscape. It was expected (based on the results of the pilot studies) that in the study proper, the subjects would respond to stimuli using expressions addressed to at least one dimension, the dominant dimension for a given metaphor: good-evil, smart-stupid, pretty-ugly, and strong-weak. For example, they would describe the moral qualities of the imagined person (good-bad) or would focus on somebody's appearance (pretty-ugly).

The stimuli represent different levels of conventionality: half were more original while the other half were as unoriginal as possible. Metaphors are seldom wholly original or completely conventional (they may be original in a given context or among a given group of language users). A complete list of the vehicles used in the study proper, their domains, dimensions, and estimated conventionality, is presented in Table 1. 
Table 1. Dimensions of Human Characteristics and Domains of Vehicles, with Estimations of Metaphors' Originality (Based on the Pilot Study).

\begin{tabular}{lcccc}
\hline $\begin{array}{c}\text { Dimension of } \\
\text { Characteristics }\end{array}$ & Animals & Plants & $\begin{array}{c}\text { Dojects of } \\
\text { Daily Use }\end{array}$ & $\begin{array}{c}\text { Elements of } \\
\text { Natural } \\
\text { Environment }\end{array}$ \\
\hline Good & dolphin (L) & apple tree (O) & cup (O) & sun (L) \\
Evil & snake (L) & nettle (O) & knife (O) & swamp (L) \\
Smart & owl (L) & - & lamp (O) & - \\
Stupid & hen (L) & - & shoe (L) & - \\
Strong & lion (L) & oak (L) & hammer (L) & rainstorm (L) \\
Weak & mouse (L) & grass (O) & cotton (O) & fog (O) \\
Pretty & butterfly O) & rose (L) & - & rainbow (L) \\
Ugly & toad (L) & potato (O) & - & murky pond (O) \\
\hline
\end{tabular}

Note: $\mathrm{L}=$ less original. $\mathrm{O}=$ more original.

\section{Analysis of the Empirical Material}

Adults were given a list of 26 metaphorical stimuli and were informed that they were possible descriptions of people. Next, the participants were asked to say what associations they had with each stimulus. The responses formed 26 sets of associations.

Then, an analysis of semantic fields was conducted: For each of the 26 sets, the number of identical expressions (or near-identical ones, differing only in gender, etc.) as well as the groups of synonyms (based on a Polish dictionary of synonyms and the opinion of competent judges - linguists) was counted. If an association was dubious, its context was taken into account. Next, identical and synonymous expressions were grouped in clusters. All the responses were included. This yielded clusters of meaning for each of the metaphors. This was enhanced with cluster analysis (clusters of synonyms) and a ratio test for dependent samples (comparison of frequency of modal category with the standard; for details, see Góralski, 1987). It was done in order to discover the properties of each of the semantic fields instead of the pattern of answers of an individual subject. Establishing dominants was necessary for further research, as it allowed to follow the dynamics in changes of meanings by studying the responses of participants from different age groups.

Dominants were determined for the 26 metaphors (i.e., the most frequent associations, the strongest clusters, etc.) as well as shades of meaning (rarer but also noteworthy associations). The magnitude of each cluster is shown by the number in brackets. The answers of adults are coded as follows: the term used by the subject - italicized; the total number of occurrences of that term 
in that semantic field - given in round brackets. The synonyms are grouped in clusters. If the number in brackets is preceded by the letter $c$, it means that the term is also the name of a cluster ( $c$ for cluster). For example, "term A (6)" means that the term A occurred six times in the semantic field of metaphor X. "Term B (c12)" means that (a) term B is a cluster of synonyms and (b) elements of cluster term B occurred in the semantic field of metaphor Y a total of 12 times. Each answer was counted but in order to clarify the text, the smallest numbers were omitted, so if the term used by a participant, italicized, is not followed by any number in brackets, it means that (a) it occurred once or twice and (b) that term may be a part of a cluster mentioned in that very sentence or paragraph.

Each and every one of the tested 26 stimuli turned out to have a unique set of metaphorical meanings. Some sets could be similar, but never the same. Each metaphor is different. The present paper only discusses those stimuli that were used as indications of "kindness": Apple-Tree, Sun, Cup, and Dolphin. Two of these metaphors are original (Human-Apple Tree, Human-Cup), one is conventional (Human-Sun), and one is located in the middle on the scale of originality (Human-Dolphin).

\section{Results}

\section{Human Apple-Tree}

Metaphor addressed to the positive end of the evil-good dimension, stimulus taken from the domain of plants, presented to 325 subjects in total (including pilot studies).

A ratio test for dependent samples (comparison of frequency of modal category with the standard) was used to compare subsequent characteristics while they were sorted from the most common to the least common. It proved to be the most original metaphor in a whole set. The Human-Apple Tree metaphor rated 1 on a scale of originality, where level 1 corresponds to the least conventional and level 7 to the most conventional metaphors, while the + symbol indicates that the presence of the principal dominant and the next most numerous one in a given semantic field was statistically significant. Dominants of Human-Apple Tree are helpful (c40, notion used by $9 \%$ of participants, principal dominant) and cheerful (c32, notion used by $6.5 \%$ of participants).

In more detail: The Human-Apple Tree metaphor is original (as expected after pilot studies), but its semantic field has a hidden pattern. The majority of participants associates it with positive aspects of social functioning, with hints towards some kind of extreme, or perfection. When subjects mention care, they mean motherly care. When they speak of sacrifice, it has to be total.

A Human Apple-Tree is good (c13). The first aspect of his/her kindness is described as altruistic, generous, giving herself, a philanthropist (2). It is 
a person that likes to bestow, shares with others, gives a lot, appeases hunger, gives shadow (in this case "shadow" had been accepted as metaphoric association with humans due to its context). Cluster helpful (c40) was composed of-among others-caring, helping hand, thoughtfulness, and respite. It is also a helpful mother, someone who acts motherly, is life-giving, generates individuals like herself, in future the apple does not fall far from the tree, and (after considering the context), is fertile (added to cluster maternal, c12). A Human Apple-Tree is associated with family (7): values his family (2), is close (2), likeness to us (after considering the context). Homely (1) and homey (2) were added to cluster homebody (c15). Other aspects of being generative, like productive, also in a creative way were added to cluster creative (c7). It is someone who develops in a positive way.

A Human-Apple Tree's character could be summed up with cluster gentle (c5): emphatic (2), having a soft, flexible character. He/she is believed to be delicate (c10), quiet (4) and polite (as civil). This serenity matches the descriptions of him/her being opened (4), warm (3), understanding (counted as tolerant), tender, and loving. Cluster nice (c14) is composed of-among others-pleasant, likeable, cordial (3), goodwill. It is a dreamer but not an introvert. One should not mistake his/her softness for weakness. Subjects combine a Human-Apple Tree's tactfulness with inner strength, rooted in his/ her emotional stability. Sober (9) and steady were added to well-balanced (c22). That person is imagined as, on the one hand, serious (2), strong (c3), adamant, resilient (as sturdy), determined (as decisive), reliable (as orderly) and, on the other, calm (14).

A Human-Apple Tree is also seen as hard-working (4). Cluster efficient (c8) was composed of-among others-providing good fruits of work, achieving success (5), giving effects of work, productive. These characteristics were easy to categorize as referring to humans. Others, however, needed a bit more looking into.

The complexity of this metaphor is reflected in associations with age: Subjects mention both the vitality of youth and the wisdom of elders. These were grouped into old (c9) and young (c11). The contrast may be spotted in old (7), elderly woman, young (8), talented and young, eternal, and fresh (4). Whenever in doubt, the competent judges analyzed the context of each and every association, and checked other notions listed by a subject in reaction to the stimuli. Therefore, fleetingness, which appeared next to sin, was taken to be understood as an abstract reflection of life itself, not necessarily a part of human characteristics. The notion eternal was positioned between bonded with tradition and experienced, and on the basics of that context, eternal was taken as an association with a topic. Fresh (4) has a complex meaning in Polish. It may be used in phrases commenting the way somebody thinks, adds his/her courageous point of view to a discussion; a person that is quick on an uptake, expresses positive emotional content, his or her general well-being, health, etc. 
In that context, fresh is a compliment, accompanied with bright, clear, comfortable, highly valued. On the other hand, fresh means unexperienced, unchecked, of an unknown quality. Subjects used phrases fresh mind, having a fresh view on a problem, having fresh opinions. Therefore, fresh was categorized as referring to characteristics of humans, it was counted twice as an association with young, and twice with intelligent. The complexity is evident as the above were accompanied with bounded to roots, conservative, old-fashioned (added to traditionalist, c7).

Some see a Human Apple-Tree as passive: a human not having opinions (as submissive), unvarying, common (as generic, c3), not acquiring attention, or boring. By others, a Human Apple-Tree could be perceived as wild, vivid, energetic (c3), and elastic (that last notion also appeared in a "human context" although doubts were raised).

It is worth noticing that this complexity should not be taken as duplicity. The characteristic part of that metaphor lies in a complete lack of any mention of dishonor, falsehood, or being prone to neither plots nor games. That feature is rare and significant, since multiple stimuli from the list were linked to portraits of liars and traitors. In adults' descriptions, being innocent, without a trace of childishness, seems to be an exception. In answers to a Human Apple-Tree, one could spot various references to truthfulness: innocent, upright, honest, straight, law-abiding, genuine, modest, direct, and upstanding. As before, preference for truth and simplicity should not be confused with simple-mindedness. A Human Apple-Tree is seen as wise (10), intelligent (2), creative (2), it is somebody that has a bright mind. He/she is reasonable (c4), pragmatic, and self-confident.

This complex set of positive intellectual traits is followed by trust. $\mathrm{He} / \mathrm{she}$ inspires trust, is somebody you can rely on, is trustworthy (c4), safe, reliable, loyal. That person is also seen as heroic and brave (c2). It may be worth noticing that the other stimulus from the plant domain, a Human Oak-Tree, had been seen as reliable and rooted in tradition. However, there are various differences. A Human Oak-Tree is "tougher" (the term tough was used 13 times in Human Oak-Tree's semantic field, while here: only once), it also has slightly more associations with sage, wise. What is missing in a Human Oak-Tree is maternity, philanthropy, cheerfulness. There is no doubt that a Human Apple-Tree is cheerful (c32). Cluster cheerful (c32) included: joyful (7), bright (4), smiling (2), beaming (2), optimistic, she/he is also light-hearted (3, joined to carefree). Only two subjects imagined him/her as sad (2). One could compare that with a semantic field of a Human-Rose: It also formed a picture of a "rooted" woman, but in a sense of "having an unyielding will" while discouraging the advances of gentlemen who were in love with her. It had nothing to do with being 'trustworthy' or 'safe' - quite the opposite. 
The advantages of a Human-Apple Tree may be observed on various levels of his/her functioning. The most often repeated is mature (10). This term can be taken as a simple association with a plant (fruits are ripe, tree has grown high, etc.), but matured was always used in a context that points to humans. To no surprise, a Human-Apple Tree is seen as socially attractive: dazzler, marvelous, and charming were joined in cluster amazing (c3). That person is supposed to be social (2), liked, as well as useful or even usable.

The strength of a Human Apple-Tree lies also in two minor threads of meaning. The first is majestic (2), dignified, distinct, proud (c3), dominant (1, as commanding). The second is: tempting, ripe (in the meaning of "ripe jokes"), sexuality, and sensual joined in naughty (c3). There were also: sin (4), worm, heaven, but the context did not establish any straight connection to humans. The term worm had been used between heaven and green, so it was classified as pointing to a vehicle.

As for the looks, only one thing is sure: A Human Apple-Tree is beautiful (c21). She is described as pretty (7), well-favored (3), handsome, full of charm, shapely (c2), proportional. It is not clear whether that person is slim or heavily built, the detailed descriptions differ: slender (c10), fat (c11), big (c6), having a vast chest, physically powerful, high (6), petite, short (2), he/she likes elegance, is round-shouldered, has a florid face (2), is sweet (c9), smells good (4, as physically attractive due to its context). A Human Apple-Tree cares about health: likes healthy food, is healthy, has a healthy style of life.

Terms categorized as associations with a vehicle include fleetingness, looks beautiful while blooming, tasty, giving apples, juicy, spring-like, colorful, grey, green (2), heaven, worm, sin. Associations with paradise, temptation, or the need of distinguishing between wrong and right were quite rare. Just one person mentioned Greek mythology (the choice of Parys, apple as an attribute of the most beautiful woman), nobody mentioned Nordic mythology (apple as a sign of Freya, the goddess of love, fertility, and death).

A Human Apple-Tree has one complex trait that distinguishes it from any other tested stimuli: It has a specific kind of protectiveness, manifested in three fields: among members of a family, in an environment of work, and in philanthropy. A Human-Apple Tree "gives itself" to others, which leads to astonishing effects.

\section{Human-Cup}

Metaphor addressed to the positive end of the good-bad continuum. Domain of stimulus: objects of everyday use. Presented to 302 adult subjects.

A ratio test for dependent samples (comparison of frequency of modal category with the standard) was used to compare subsequent characteristics while they were sorted from the most common to the least common. The Human-Cup metaphor proved to be original (as expected), it was rated $1+$ on a scale of originality. As mentioned above, level 1 indicates the least 
conventional metaphors while level 7 marks the most conventional ones. The + symbol indicates that the presence of the principal dominant and the next most numerous one in a given semantic field was statistically significant. The dominants of a Human-Cup metaphor are: fat (c44, notion used by $11 \%$ of participants, principle dominant), warm (c33, notion used by $9 \%$ of participants). The clusters of fat, warm, useful, common, nice, and a reference to the vehicle, were more common than others, the distinction was statistically significant. The rest of the semantic field will be analyzed below. Many answers were descriptive and imaginative: They did not form strict clusters but a complex, multilayered picture that is coherent. Further investigations allowed comparisons with groups of younger participants (results not shown here; for more, see Dryll \& Bokus, 2016).

That set of dominants forms a result that stands against expectations. The "cup" stimulus was chosen for the list used in the study proper after a set of pilot studies in which the group of participants had been formed of psychology students. Their inclination towards analyzing social functioning may have influenced the results. After completing the study proper, the Human-Cup metaphor turned out to have a different meaning: Instead of being a symbol of abstract ideas, it is often associated with physical features, privacy, and safety. It is linked with things that are well known, common, suitable, and tamed. Nothing fancy, just plane usefulness and practicality. What is characteristic for a Human-Cup is the combination of ordinariness, familiarity, and being "socially warm." Hence, the descriptions: useless and empty or hot and passionate - depending on whenever he/she has somebody close to him/her (counted as submissive), empty, but warm towards people, empty but sometimes useful. In a way, a Human-Cup is "good," but not in a context of discussing abstract traits and moral dilemmas. Its goodness lies in being useful, prone to fulfilling demands, disposable, undemanding, and inactive until needed.

Let us take a closer look at that "emptiness." Sometimes subjects added further details to their first associations. If taken together, the details form a pattern. Empty (29), not having any opinions, devoid of one's own opinions, supine, being susceptible for influence, at one's disposition, submissive (c5), susceptible for influence (as submissive). On the other hand, four subjects imagined a Human-Cup as full (4), but, unfortunately, did not give details. Full of what? Full of emotions? One subject adds full of optimism, one mentions being rich on the inside. A person imagined as a Human-Cup is supposed to be simple (7, as straightforward, c8). Another subject uses a term that has a lot of meanings in Polish: próżny, which combines empty with vain and futile. It matches an object that serves for pouring fluids in and out. However, the context showed, that that subject probably meant a human trait. 
The thread of associations is intriguing. Subjects say that a person is empty because he or she has no character - meaning that they find it hard to observe signs of self-reliant thinking or inner motivation. Such an individual behaves as if he or she was activated only in response to an external impulse. In our culture, adults often declare that intentions are more important than the results of one's actions. Therefore, it may be hard to say that an inactive person is "good" in the meaning of "being a moral agent." "Being a good human" depends on maintaining a standard - one has to act of free will, choose to speak the truth, be brave, sacrifice, defend the weaker, be conscious of faults, restrict oneself, and resist temptations. In other words, we expect the "good people" to be constantly heroic in multiple aspects of life. Being devoid of self-regulation or self-control could be seen as a sign of weakness or stupidity. Some participants pictured a Human-Cup from that angle, but it was not an exuberant cluster: stupid (c15) was a composition of foolish, thick, dull, slow-witted, and unintelligent. To one subject, he/she is also boring. On the other hand, this lack of intellectual or emotional inner struggle combined with selfless responsiveness to the needs of others could be understood as some sort of maturity. A Human-Cup is certainly safe from overthinking. Maybe he/she is resistant to the demands of the ego? His/her simplicity could point to that but since there are so many ways in which one could be "simple," it is too early to assert that. One subject described a Human-Cup as a bottomless person - has a lot of ideas. There was just one other apparition of imaginative.

Other threads add to the picture of a Human-Cup's objectification. Notions of trivial and prosaic were added to common (c26), while insignificant and the one that does not contribute anything new to life were counted as unneeded (c2). Some subjects see him/her as an undistinguished person, featureless (c2), boring (5), or inept. He/she is also seen as lazy and dreary, slow, and phlegmatic (c3). These responses might lead to a conclusion that a Human-Cup is often treated as an object of manipulation. The reason for that may be obvious: The vehicle (cup) had been taken from the domain of everyday objects. It seems only natural to imagine the topic in the context of the vehicle's usefulness. However, the analysis of semantic fields of other metaphors that had vehicles taken from the same domain (Human-Key, Human-Lamp, Human-Book, Human-Bandage) shows that it is not that simple. For example, a Human-Lamp is a spiritual leader. Its descriptions are grouped around associations with "bright mind," intellectual independency, and being an example for others. Here, a Human-Cup's inactivity is probably based on the properties of the vehicle itself, not only its domain.

As it often happens, some subjects name the traits that belong to the same category, but to another vector. Some sets of associations point to various forms of strength or intensity: haughty, severe, tough (4), decisive (3), realistic, pragmatic, active, confident, terse, tough-skinned (counted as arrogant). 
A Human-Cup is seen as persistent, sturdy, hard-working, and reliable (3). These statements were few, but they add to the picture of a tool. However, the percentage of these were so small that they did not collide with the main image of a Human-Cup that still seems to be an ideal object of manipulation. $\mathrm{He} / \mathrm{she}$ has to be given a goal, or set on a track. After that, one just waits for a result. That suits other parts of description-associations: satisfying, gratifying the needs of others, convenient, exploitable (10), etc. were added to the cluster useful (c28). In each of these, the context pointed to humans. Two answers addressed the same category of traits but the opposite vector: easily given back and useless (c2, unneeded). A Human-Cup is also ever accessible (as opened $\mathrm{c} 6$ ) and practical (c11). Here, it was uncertain whether the subjects thought about humans or objects as the answers were too laconic to build a context.

Some subjects composed these flaws with mentions of a Human-Cup's emotionality. He/she is not imagined as a person in need of adrenaline. Sober (5), a staid person, settled down, consistent in his/her actions (c4), dependable, calm (c12), restrained. A Human-Cup is focused on domestic interests: a person devoted to family, homebody, stay-at-home (c15). Once again, we see the commonness but this time, from a different perspective. A Human-Cup is often overlooked but his/her lack of social activity may be a result of a conscious decision. A person that values intimacy, an introvert (c2) that does not like to stand out (as shy). One participant grasped Human-Cup's liking for stability and constancy -in single association: traditionalist.

Despite all flaws, a Human-Cup is often liked. The most probable explanation is that he/she has an amiable character. His/her advantages form a coherent picture. Cluster helpful (c12) includes helpful (7), likes to help, soothing (2), protective, and protects. He/she is a person that likes giving advice, knows how to listen (as nice), and can be trusted (c4, as worth of trust). He/she is also honest and patient (as persistent). One of the main traits of a person imagined as a Human-Cup is his/her personal warmth. Cluster warm (c33) is quite strong and homogeneous, slightly fortified with tender and hot (hot may mean many things; here, the context pointed to emotional intensity instead of high temperature, sex appeal, etc.). Cluster nice (c21) included has a positive attitude and a good fellow. Other descriptions showed him/her as gentle, joyful (2, as cheerful), opened for novelty (5), sociable (2), and curious (as inquisitive).

The statements mentioned above picture him/her as a marionette or as a reliable introvert. But that is far from over. According to some subjects, a Human-Cup enjoys the pleasures of life: broad, promiscuous, talkative, and cheerful (c8), or sad, funny. A Human-Cup likes to overhear (c2, as curious) - an association that might come from the fact that most cups have a handle (called "ear" in Polish) or from a method of overhearing, described 
in various children's books and crime stories (put a glass to a wall). As if that was not enough, a Human-Cup could be taken as infantile, childish (c2), artificial, fake, eccentric, and individualistic. Here, his/her emotional stability is enriched with fluctuant in feelings, variable, it is easy to hurt him, and brittle (4). He/she cannot cook, is weak (c6), and delicate (2). The numbers are not high but all associations are worth noticing, as they complete the description. One subject added that he/she is gay. Mentions of his/her fondness for warmth and fond of comfort (2) were added to cluster expedient (c11). Sleepy, with dark circles under eyes, and sleepyhead were accompanied with lovable. As we see, a metaphor of a Human-Cup proves to have a complex semantic field. As for the apparition, Human-Cup is imagined as: fat (c44), including pot-bellied (5), and round (6). He or she is small (2), short, of a normal built, thin, with grand ears or ugly (2).

As explained in earlier paragraphs, all answers were counted and analyzed. In the opinion of competent judges, some associations might not be addressed directly to humans: with warm chocolate or water, water, tea, just next to learning, coffee, slaking the thirst, similarities, similar, identical, with an ear (a cup's handle is called "ear" in Polish), home, beverage, volume, for drinking, capacious, static, colorful (4), tasteful, handy (2), detachment, safety, etc. Terms such as nonsolid, solid, steady were also classified as associations with vehicle due to their direct context.

\section{Human-Sun}

Metaphor addressed to the positive end of the good-bad continuum. Domain of stimulus: elements of natural environment. Shown to 226 adult subjects.

The Human-Sun metaphor proved to be highly conventional as it rated 7 on a scale of originality. Level 7 indicated the most conventional metaphors. As before, a ratio test for dependent samples (comparison of frequency of modal category with the standard) was used to compare subsequent characteristics while they were sorted from the most common to the least common. Dominants of the Human-Sun metaphor: cheerful (c199, notion used by $88 \%$ of participants), warm (c49, notion used by $21 \%$ participants) and nice (c34, notion used by $16 \%$ participants).

The results of the pilot study have shown that this stimulus could be used to point to a person that seems to be close to an ideal: outstandingly talented and generally marvelous. Participants of that pilot study wrote descriptions that included notions such as noble, honorable, worthy, and dignified. Some answers suggested a picture of a person with unequalled moral standard. However, the main study showed that a Human-Sun is mainly just cheerful (c199). His/her presence is a source of joy and encouragement for others. He/she brightens things up (context points to humans), bucks the atmosphere, cheers others up (2), passes on the smiles, provides positive 
energy to everyone and gives the feeling of closeness. That person is somebody who warms others up, is hot, and warm (c49). One subject connected it with passionate, but other associations are more frequent: radiant (12), bright (24), an optimist (19), active and energetic (c9), spontaneous, opened (5), social (c5). He/she is a spirit of a company, and is funny. Descriptions such as somebody we like, precious for another, loved, and close relation were added to cluster liked (c12). As expected, the semantic field contains the notion nice (c34), which included pleasant (6), friendly (7), cordial (3).

Terms such as selfless and helpful were added to cluster good (c11) instead of to sociable or cordial because, as the competent judges pointed out, the context suggests a Human-Sun's basic values, deeper meaning, and involvement - not just him/her being a fine companion. Some other objects of metaphors were deciphered as nice, but giving hope seems to go far beyond common pleasantries. Even though cluster good (c11) is small in numbers, it is well coordinated with other positive aspects of a Human-Sun. He/she is imagined as a person that is a source of life energy, warmth, and light.

To no surprise, the semantic field of a Human-Sun metaphor is somehow similar to the semantic field of a Human-Lamp. However, contrary to expectations, a sun is not a "bigger lamp." The majority of a Human-Lamp's semantic field is devoted to his/her intellectual functioning. In response to a Human-Sun, just 20 subjects used terms classified as belonging to cluster bright (c20), three used enlightened, sapient, having a bright mind. One subject speaks of honesty and another about transparency. A Human-Sun is also supposed to be real (as honest), straightforward and calm, but these singular answers cover a small part of the semantic field.

Polish has a popular phrasal verb that means "engaging oneself in an action that cannot be completed or results in success" - its rough, literal translation would be as follows: "to sweep oneself with a hoe towards the sun." One could expect that a Human-Sun represents a person that would be highly attractive and beyond reach due to his/her social status, looks, or other desired features. Alas, it is not so. Or not entirely. Just a few subjects mentioned a trait that would suggest some kind of social distance. There is a trace of being "a spirit of a company," but without being a celebrity or a star (an association sun-star would be completely natural). One participant uses famous, one other worthy of admiration, and yet another conspicuous, which were joined in cluster liked (c3). Mythical threads of "God's chariot" or "heaven's eye" were not directly activated, but few terms bore semantic resemblance to that grandeur: almighty, determinant, knows everything, exceptional, important, significant, and ego-man. Nevertheless, a Human-Sun is not always taken as everlasting: young, childish, and innocent.

A Human-Sun looks beautiful (c14), has a chubby face, is petite, or big. Two subjects thought about vacation: fond of lying on a beach, and sunbathing. The rest of the answers were classified as references to the vehicle: summer, 
health, Asian. The competent judges decided that neuter type adjectives point to the vehicle. Therefore, these answers were classified as non-figurative, but still, it is worth noting them down: grand and merciful, crucial, slowcoach, tired.

\section{Human-Dolphin}

Metaphor addressed to the positive end of the good-bad continuum. Stimulus taken from the domain of animals. Shown to 263 adult subjects.

The Human-Dolphin metaphor rated 4 on the scale of originality. As before, a ratio test for dependent samples (comparison of frequency of modal category with the standard) was used to compare subsequent characteristics while they were sorted from the most common to the least common. Three differences were statistically significant: The most popular notion was gadabout (c141, a notion used by $22.5 \%$ of the participants). Second in popularity were nice (c107, notion used by $17 \%$ of the participants), and intelligent (c52, notion used by $8 \%$ of the participants). Other terms and clusters stood apart as rare (in comparison).

A Human-Dolphin is generally liked. It is associated mainly with providing help and, importantly, doing so cheerfully, willingly, and without any hidden agenda. Cluster helpful (c29) is composed of, among others: obliging (2), aiding in need (4), and healing. Terms such as good (6), good-natured, selfless, noble, fine, goodie were joined in cluster good (c13) while kind (44), friendly (24), pleasant (12), cordial (2), congenial (2), collegial, and amiable were joined in cluster nice (c107).

A Human-Dolphin is frequently described as free-spirited and lightheaded. It is one that likes and values freedom. Cluster gadabout (c141) included frivolous (c85), carefree (3), and playful, while funny and prankster formed cluster amusing (c2). He/she is also entertaining, having a sense of humor, adorable, delightful (2) - a sweetie (c7). That person is supposed to be an optimist. A Human-Dolphin is social (c11). This positivity and social skills may go slightly deeper than the ability to engage in small-talk: maintaining $a$ bond with close ones, humane, faithful, honest, frank, trusting, opened, warm, emotional, remarkable, in-love, love, and full of hope. That is what makes $\mathrm{him} / \mathrm{her}$ popular, adored, and loved (in cluster liked c4). A Human-Dolphin, despite his/her light-headedness, does not seem to be boisterous. He/she is protective. That drive for helping others is composed with sensitivity (c6), gentleness (8), serenity (6), and empathetic understanding.

One could suppose that being carefree is a weakness. However, the analysis of various semantic fields shows that the subject's attitude may be reflected in a larger picture - a compilation of elements included. For example, "being carefree," in case of a Human-Dolphin, is joined with his/her willingness to support others and with his/her intellectual abilities. It is not a lack of common sense that makes Human-Dolphin optimistic. He/she is 
imagined as wise (32). Terms such as clever (6), smart (4), and witty were added to cluster intelligent (c52). One subject uses capable while another uses a bit mysterious kind, but ambitious. Dolphin is simply not bothered by worldly misfortunes, as long as they don't affect his/her close-ones. That forms a slightly different perspective to being lightheaded, if compared to a HumanButterfly or a Human-Fog. Neither Human-Fog nor Human-Butterfly are strong but, according to the subjects, their fragility is linked to indecision and inconstancy. Both show volatility of whims, both try to be misleading, and take pride in being mysterious. Subjects speak of their immaturity despite of adulthood - one can be of age but act childishly. Here, we have a different picture. Human-Dolphin is not burdened with duties and responsibilities, he/she is free (c21 - included independent (2), unrestrained). Cluster energetic (c16) incorporated active (2), fidgety (3), person full of energy, and hyperactive. That fondness of freedom may lead to perceiving him/her as inaccessible (2) or elusive. Human-Dolphin is naive (2), innocent, and used. But, at the same time, he/she is trustworthy (c2). Therefore, he/she combines traits of a good child and a trusting, optimistic adult - a youngster (3). A Human-Dolphin was not once called bloke, dude, crony, sod, dawg, matey or anything like that - a term used in Polish mtodzieniec (youngster) is far from slang: It is slightly archaic but shows a kind of nobility and light irony.

A youngster's strength has two consequences: effectiveness and mobility. A Human-Dolphin is sportive (c10), a swimmer (9). Lithe (2), graceful (2), and flexible (2) were joined in adroit (c27). He/she is described as slender (7) and agile (30). That person is also determined, powerful, strong, fast at reaching a goal (as effective), and manly. He/she is a perfectionist.

Single individuals added that Human-Dolphin is inscrutable, and dangerous. There were surprisingly little associations with the French term for crown prince - just one: a youngster in queue for the crown, all-important, dignified, bossy, and snob. Again, one subject wrote he/she is gay.

A Human-Dolphin looks pretty, beautiful (c18), very friendly in looks, slim (2). The terms taken as referring to a vehicle include wet, weird (2), untypical, slimy, mammal, flat, teres, washing up, streamlined, sea (2), and sister. An association with a sea mammal found its mark in often speaks in ultrasound (taken as referring to an animal), barely anybody can hear him, reticent, silence, loud.

\section{Discussion}

What is a metaphoric picture of a "kind human" made of? The text above pictures the semantic fields of four target metaphors: Human-Apple Tree, Human-Sun, Human-Cup, and Human-Dolphin. They show four complex characteristics. Each is built of a unique set of associations, but they also share 
basic elements. These are, in short: kindness, caregiving, serenity, selflessness, diligence, stamina. Is this picture compatible with 'warmth' described in the theory? It probably is.

Kindness seems to be built on the willingness to help. Help takes various forms. From giving life (a mother), providing warmth, joy, hope, a wise advice, an ear to listen, to sharing fruits of work and being generally "usable." What connects these is that help is given willingly, generously, and without hesitation. Truthfulness and honesty are essential here - help has to be unconditional, maybe even irrational. There was no mention of calculations nor plots like "helps those worth saving" or "is nice, provided you do him favors." Benefactor expects nothing in return.

Reservations about a Human-Cup's agency are in accordance with what Pizarro and Tannenbaum (2011) say about person-based approach in the history of research on moral judgement. Person-based approach focuses on the person's traits, dispositions, and character when judging blame - to be held responsible for an act, one must have had the ability to do otherwise. If an individual had no control over an action, did not intend or foresee the infraction, then holding that individual blameworthy would be unjustified. A Human-Cup is submissive. But not as passive as to be deprived of moral agency. It seems that it is a picture of a selfless person, a person that knowingly lets others use him/her.

The first associations with the concept of powerlessness are often negative. The belief that in order to be happy, one has to be active, responsible, and self-confident has deep roots in western culture. However, metaphors of powerlessness have been found in the context of substance abuse recovery - in its developmental and process oriented phase (Matheson \& McCollum, 2008). Some subjects indicated positive emotions around powerlessness (relief) whereas others indicated negativity (fear). That perspective shows powerlessness in a different light. As if, at times, powerlessness was close to acceptance safety.

Other striking resemblance between the four semantic fields is the cheerfulness combined with serenity. For adults, being supportive means being in good spirits. Not in fits of laughter, but far from being somber either. None of these sets portray a grim, brooding moralizer. The benefactor needs to be reliable and serious-minded but, at the same time, flexible, cheerful, and light in his/her ways. It is about balance. Due to being kind, caring, wise, strong, mentally stable and due to behaving in a predictable way, one becomes a never-ending source of energy for others. Always on duty. 


\section{References}

Baldwin, C. P., \& Baldwin, A. L. (1970). Children's judgments of kindness. Child Development, 41(1), 29-47. doi:10.2307/1127387

Bartczak, M., \& Bokus, B. (2013). Rozumienie pojęć w depresji. [Understanding metaphors in depression]. Piaseczno: LEXEM.

Białecka-Pikul, M. (2003). Metaphors in preschool child thinking about the mind. Psychology of Language and Communication, 7(2), 37-47.

Black, M. (1979). More about metaphor. In A. Ortony (Ed.), Metaphor and thought (pp. 19-43). Cambridge, MA: Cambridge University Press.

Bloom, P. (2013). Just babies: The origins of good and evil. New York, NY: Crown.

Boroditsky, L. (2000). Metaphoric structuring: Understanding time through spatial metaphors. Cognition, 75(1), 1-28. doi:10.1016/S0010-0277(99)00073-6

Brambilla, M., \& Leach, C. W. (2014). On the importance of being moral: The distinctive role of morality in social judgment. Social Cognition, 32(4), 397-408. doi:10.1521/soco.2014.32.4.397

Brambilla, M., Rusconi, P., Sacchi, S., \& Cherubini, P. (2011). Looking for honesty: The primary role of morality (vs. sociability and competence) in information gathering. European Journal of Social Psychology, 41(2), 135-143. doi:10.1002/ejsp.744

Chandler, M. J., Greenspan, S., \& Barenboim, C. (1973). Judgments of intentionality in response to videotaped and verbally presented moral dilemmas: The medium is the message. Child Development, 44(2) 315-320. doi: $10.2307 / 1128053$

Chiappe, D. L., Kennedy, J. M., \& Chiappe, P. (2003). Aptness is more important than comprehensibility in preference for metaphors and similes. Poetics, 31, 51-68. doi:10.1016/S0304-422X(03)00003-2

Chiappe, D. L., Kennedy, J. M., \& Smykowski, T. (2003). Reversibility, aptness, and the conventionality of metaphors and similes. Metaphor and Symbol, 18(2), 85-105. doi:10.1207/S15327868MS1802_2

Colby, A., Kohlberg, L., Gibbs, J., Lieberman, M., Fischer, K., \& Saltzstein, H. D. (1983). A longitudinal study of moral judgment. Monographs of the Society for Research in Child Development, 48(1-2), 1-124. doi:10.2307/1165935

Cuddy, A. J., Fiske, S. T., \& Glick, P. (2008). Warmth and competence as universal dimensions of social perception: The stereotype content model and the BIAS map. Advances in Experimental Social Psychology, 40, 61-149. doi:10.1016/S0065-2601(07)00002-0

Cushman, F. (2008). Crime and punishment: Distinguishing the roles of causal and intentional analyses in moral judgment. Cognition, 108, 353-380. doi:10.1016/j.cognition.2008.03.006 
Cushman, F., Young, L., \& Hauser, M. (2006). The role of conscious reasoning and intuition in moral judgment: Testing three principles of harm. Psychological Science, 17, 1082-1089. doi:10.1111/j.1467-9280.2006. 01834.x

Dryll, E. M. (2009). Changes in metaphor comprehension in children. Polish Psychological Bulletin, 40(4/2009), 49-57. doi:10.2478/s10059-009-0015-1

Dryll, E. M. (2017). Metaphorical descriptions of wrongdoers. Psychology of Language and Communication, 21(1), 171-191. doi:10.1515/plc-2017-0009

Dryll, E. M., \& Bokus, B. (2016). Zrozumieć metaforę: Studium z psycholingwistki rozwojowej [Understanding metaphors: A study in developmental psycholinguistics]. Piaseczno: LEXEM.

Dryll, E. M., \& Bokus, В. (2018). Разбиране от деца и юноши на метафори, описващи хора [Children's and adolescents' comprehension of metaphors describing people]. Ezik i Literatura [Language and Literature]. No. 1-2, 9-26. Print ISSN: 0324-1270 Online ISSN: 2535-1036 Retrieved from http:// www.ezik-i-literatura.eu/2018/1-2/2-Dril-Bokus

Fiske, S. T., Cuddy, A. J., \& Glick, P. (2007). Universal dimensions of social cognition: Warmth and competence. Trends in Cognitive Sciences, 11(2), 77-83. doi:10.1016/j.tics.2006.11.005

Gantman, A. P., \& Van Bavel, J. J. (2015). Moral perception. Trends in Cognitive Sciences, 19(11), 631-633. doi:10.1016/j.tics.2015.08.004

Gentner, D. (1983). Structure-mapping: A theoretical framework for analogy. Cognitive Science, 7, 155-170. doi:10.1207/s15516709)og0702_3

Gentner, D., \& Clement, C. A. (1988). Evidence for relational selectivity in the interpretation of analogy and metaphor. In G. H. Bower (Ed.), The psychology of learning and motivation, (pp. 307-358). New York, NY: Academic Press.

Gibbs R. W. Jr (2001). Evaluating contemporary models of figurative language understanding. Metaphor and Symbol, 16(3-4), 317-333. doi:10.1080/1092 6488.2001 .9678900

Gibbs, R. W. Jr (2002). The poetics of mind. Figurative thought, language, and understanding. Cambridge, MA: Cambridge University Press.

Glucksberg, S. (2003). The psycholinguistics of metaphor. Trends in Cognitive Sciences, 7(2), 92-96. doi:10.1016/S1364-6613(02)00040-2

Glucksberg, S. (2008). How metaphors create categories-quickly. In R. W. Gibbs $\mathrm{Jr}$ (Ed.), The Cambridge handbook of metaphor and thought (pp. 67-83). Cambridge, MA: Cambridge University Press.

Glucksberg, S., \& Haught C. (2006). On the relation between metaphor and simile: When comparison fails. Mind and Language, 21(3), 360-378. doi.org/10.1111/j.1468-0017.2006.00282.x

Glucksberg, S., \& Keysar, B. (1990). Understanding metaphorical comparisons: Beyond similarity. Psychological Review, 97, 3-18. doi:10.1037/0033295X.97.1.3 
Gottwald, J. M., Elsner, B., \& Pollatos, O. (2015). Good is up: Spatial metaphors in action observation. Frontiers in Psychology, 6, 1605. doi:10.3389/ fpsyg.2015.01605

Góralski, A. (1987). Metody opisu $i$ wnioskowania statystycznego dla psychologów i pedagogów [Methods of description and statistical reasoning for psychologists and pedagogues]. Warsaw: PWN.

Graham, J., Nosek, B. A., Haidt, J., Iyer, R., Koleva, S., \& Ditto, P. H. (2011). Mapping the moral domain. Journal of Personality and Social Psychology, 101, 366-385. doi:10.1037/a0021847

Graves, M. P. (1983). Functions of key metaphors in early Quaker sermons, 1671-1700. Quarterly Journal of Speech, 69(4), 364-378. doi:10.1080/00335638309383663

Gray, K., Young, L., \& Waytz, A. (2012). Mind perception is the essence of morality. Psychological Inquiry, 23(2), 101-124. doi:10.1080/1047840 X.2012.651387

Hamlin, J. K., Wynn, K., \& Bloom, P. (2007). Social evaluation by preverbal infants. Nature, 450(7169), 557.

Karylowski, J. (1982). Doing good to feel good v. doing good to make others feel good: Some child-rearing antecedents. School Psychology International, 3(3), 149-156. doi:10.1177/0143034382033004

Kennedy, J. M., \& Chiappe, D. L. (1999). What makes a metaphor stronger than a simile? Metaphor and Symbol, 14, 63-69. doi:10.1207/s153278 $68 \mathrm{~ms} 14017$

Kubicka, D. (2005). Myślenie metaforyczne i jego uwarunkowania u dzieci w wieku od 4 do 10 lat [Make strange familiar and make familiar strange: Metaphoric thinking in children from 4 to 10]. Studia Psychologiczne, 43(2), 59-73.

Lakoff, G., \& Johnson, M. (1980). Metaphors we live by. Chicago, IL: University of Chicago Press.

Lapsley, D. K., \& Lasky, B. (2001). Prototypic moral character. Identity: An International Journal of Theory and Research, 1(4), 345-363. doi:10.1207/ S1532706XID0104_03

Levin, I., \& Bekerman-Greenberg, R. (1979). Moral judgment and moral behavior in sharing: A developmental analysis. Israeli Journal of Psychology \& Counseling in Education, 11, 24-34.

Littlemore, J., \& Low, G. (2006). Metaphoric competence, second language learning, and communicative language ability. Applied Linguistics, 27(2), $268-294$.

Markman, A. B., \& Gentner, D. (1990). Analogical mapping during similarity judgments (Ed.), Proceedings of the twelfth annual conference of the cognitive science society (pp. 38-44). Cambridge, MA: Cognitive Science Society. 
Matheson, J. L., \& McCollum, E. E. (2008). Using metaphors to explore the experiences of powerlessness among women in 12-step recovery. Substance Use \& Misuse, 43(8-9), 1027-1044. doi:10.1080/10826080801914287

Nippold, M. A., \& Fey, S. H. (1983). Metaphoric understanding in preadolescents having a history of language acquisition difficulties. Language, Speech, and Hearing Services in Schools, 14(3), 171-180. doi:10.1044/0161-1461.1403.171

Noveck, I. A., Bianco, M., \& Castry, A. (2001). The costs and benefits of metaphor. Metaphor and Symbol, 16(1-2), 109-121. doi:10.1080/1092648 8.2001 .9678889

Ortony, A. (1979). Beyond literal similarity. Psychological Review, 86(3), 161-180. doi:10.1037/0033-295X.86.3.161

Ortony, A. (Ed.). (1993). Metaphor and thought (2nd ed.). Cambridge: Cambridge University Press.

Ortony, A., Vondruska, R. J., Foss, M. A., \& Jones, L. (1985). Salience, similes, and the asymmetry of similarity. Journal of Memory and Language, 24(5), 569-594. doi:10.1016/0749-596X(85)90047-6

Peterson, L. (1980). Developmental changes in verbal and behavioral sensitivity to cues of social norms of altruism. Child Development, 51(3), 830-838. doi:10.2307/1129471

Peterson, L., Hartmann, D. P., \& Gelfand, D. M. (1977). Developmental changes in the effects of dependency and reciprocity cues on children's moral judgments and donation rates. Child Development, 48(4), 1331-1339. doi:10.2307/1128491

Pisula, E. (2003). Cognitive and social aspects of communication deficits in children with autism. Psychology of Language and Communication, 7(2), 49-67.

Pizarro, D. A., \& Tannenbaum, D. (2011). Bringing character back: How the motivation to evaluate character influences judgments of moral blame. In P. Shaver \& M. Mikulincer (Eds.), The social psychology of morality: Exploring the causes of good and evil (pp. 91-108). Washington, DC: American Psychological Association.

Ricoeur, P. (1978). Metaphorical process as cognition, imagination, and feeling. Critical Inquiry, 5(1), 143-159. doi:10.1086/447977

Rudnicka, E. (2004). Znaczenie metaforyczne $w$ polskiej tradycji stownikarskiej: Studium leksykologiczno-leksykograficzne. [Metaphorical significance in Polish dictionary tradition: Lexicological and lexicographical study]. Warszawa: Semper.

Saltzstein, H. D., \& Weiner, A. S. (1982). Moral intentionality: Children's representation of adult judgments and attribution processes. Paper presented at the annual meeting of the American Psychology Association, Washington, DC. 
Shure, M. B. (1968). Fairness, generosity, and selfishness: The naive psychology of children and young adults. Child Development, 39(3), 875-886. doi: $10.2307 / 1126990$

Sims, S. A. (1978). Sharing by children: Effects of behavioral example, induction, and resources. The Journal of Psychology, 100(1), 57-65. doi:10.1080/0022 3980.1978 .9923471

Skitka, L. J. (2010). The psychology of moral conviction. Social and Personality Psychology Compass, 4(4), 267-281. doi:10.1111/j.1751-9004. 2010.00254.x

Smith, C. L., Gelfand, D. M., Hartmann, D. P., \& Partlow, M. E. (1979). Children's causal attributions regarding help giving. Child Development, 50(1), 203-210. doi:10.2307/1129057

Tannenbaum, D., Uhlmann, E. L., \& Diermeier, D. (2011). Moral signals, public outrage, and immaterial harms. Journal of Experimental Social Psychology, 47(6), 1249-1254. doi:10.1016/j.jesp.2011.05.010

Walker, L. J., \& Hennig, K. H. (2004). Differing conceptions of moral exemplarity: Just, brave, and caring. Journal of Personality and Social Psychology, 86(4), 629. doi:10.1037/0022-3514.86.4.629

Weiss, R. J. (1982). Understanding moral thought: Effects on moral reasoning and decision making. Developmental Psychology, 18(6), 852. doi:10.1037/00121649.18.6.852

Woolfolk, R. L., Doris, J. M., \& Darley, J. M. (2006). Identification, situational constraint, and social cognition: Studies in the attribution of moral responsibility. Cognition, 100, 283-301. doi:16/j.cognition.2005.05.002

Veale, T., \& Hao, Y. (2007). Learning to understand figurative language: From similes to metaphors to irony. Proceedings of the Annual Meeting of the Cognitive Science Society, 29(29), 683-688.

Ybarra, O., Chan, E., Park, D. (2001). Young and old adults' concerns about morality and competence. Motivation and Emotion. 25(2), 85-100.

Young, L., \& Saxe, R. (2011). When ignorance is no excuse: Different roles for intent across moral domains. Cognition, 120(2), 202-214. doi:10.1016/j. cognition.2011.04.005 